\title{
Selective area epitaxy of magnesium oxide thin films on gallium nitride surfaces
}

\author{
Mark D. Losego a),b) \\ School of Materials Science and Engineering, Georgia Institute of Technology, Atlanta, Georgia 30332, USA \\ Elizabeth A. Paisley ${ }^{b}$ \\ Sandia National Laboratories, Albuquerque, New Mexico 87185, USA \\ H. Spalding Craft, Peter G. Lam, Edward Sachet, Seiji Mita, Ramon Collazo, Zlatko Sitar, and Jon- \\ Paul Maria \\ Department of Materials Science and Engineering, North Carolina State University, Raleigh, North Carolina \\ 27695, USA
}

(Received 24 June 2015; accepted 9 October 2015)

Selective area growth of thin films reduces the number of steps in microfabrication processing and enables novel device structures. Here, we report, for the first time, selective area epitaxy of an oxide material on a $\mathrm{GaN}$ surface. Chlorination of the $\mathrm{GaN}$ surface via wet chemical processing is found effective to disrupt $\mathrm{Mg}$ adsorption and selectively prevent molecular beam epitaxy growth of $\mathrm{MgO} . \mathrm{MgO}$ films grown on neighboring, nonchlorinated surfaces are epitaxial with a (111) $\mathrm{MgO} \|(0001) \mathrm{GaN}$ crystallographic relationship. Better than $3 \mu \mathrm{m}$ lateral resolution for the selective area growth of $\mathrm{MgO}$ on $\mathrm{GaN}$ is demonstrated.

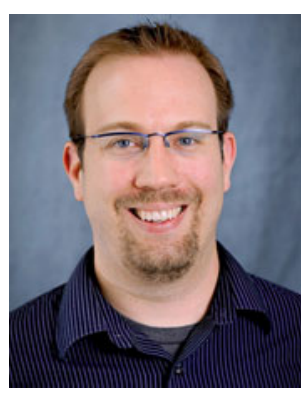

Mark D. Losego

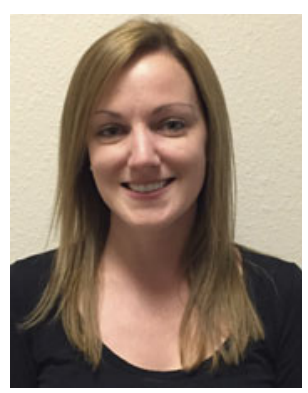

Elizabeth A. Paisley

Mark D. Losego is an Assistant Professor of Materials Science and Engineering at Georgia Tech. He received his B.S. from Penn State in 2003 and his M.S. (2005) and Ph.D. (2008) from NC State, all in materials science. Prior to joining the faculty at Georgia Tech in 2014, he conducted postdoctoral research in nanoscale heat transport at the University of Illinois and led investigations into solar fuels as a research faculty at NC State. Currently, his research group has interests in advanced materials synthesis for renewable energy, national security, and microelectronics applications. The research presented here originates from a series of "failed" experiments conducted during Prof. Losego's Ph.D. studies. During a 6 mo period, research nearly halted because $\mathrm{MgO}$ films could no longer be grown on GaN surfaces above $250{ }^{\circ} \mathrm{C}$. Through persistence, detailed documentation, and careful observation, Prof. Losego discovered that a simple change in the order of the surface cleaning steps had prevented the film growth. It is hoped that this example of "success through failure" will motivate current and future graduate students as they navigate through the inevitable struggles of their research careers.

Elizabeth A. Paisley is a postdoctoral researcher at Sandia National Laboratories in the Electronic, Optical, and Nano Materials Department. She received her B.S. in 2008 and her Ph.D. in 2012 from North Carolina State University, both in Materials Science and Engineering. Before her work at Sandia, Elizabeth spent two years studying growth and characterization of AlN, GaN, and AlGaN alloys on native AlN substrates at HexaTech, Inc. for UV-C LED applications. Currently, in her postdoctoral research she focuses on oxide thin film research for GaN and AlGaN power electronics.

Contributing Editor: Cewen Nan

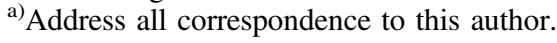
e-mail: losego@gatech.edu

b) These authors contributed equally to this work. DOI: $10.1557 / j m r .2015 .332$

\section{INTRODUCTION}

Lateral patterning of thin films is essential for the fabrication of integrated circuits and other microdevices. A typical patterning sequence includes thin film deposition, resist application, lithographic patterning, etching, and resist removal. This series of steps is time 
consuming, can lower the quality of the deposited material and/or interface, and can introduce registry misalignment between patterned layers. Deposition processes that lead to self-directed lateral patterning during film growth are highly sought to lower costs and improve performance of devices.

Examples of selective area epitaxy (SAE) for III-V and II-VI semiconductors are prevalent in the metalorganic chemical vapor deposition (MOCVD) community. MOCVD SAE has been demonstrated for most of the III-V and II-VI semiconductors including GaAs, ${ }^{1,2}$ $\mathrm{GaN},{ }^{3}$ InAs, ${ }^{4}$ and $\mathrm{ZnSe} .^{5}$ This ability to laterally pattern III-V and II-VI semiconductors in a single growth step has led to advances in microelectronics, ${ }^{6,7}$ optoelectron$\mathrm{ics}^{8}{ }^{8}$ and photonics ${ }^{9}$ technology. In MOCVD of III-V and II-VI semiconductors, selectivity is typically achieved by applying oxide or nitride masks that force SAE on exposed semiconductor regions. The higher sticking coefficient for III-V or II-VI MOCVD precursors on semiconductor surfaces versus oxide or nitride surfaces is the generally accepted mechanism for selectivity. By controlling super-saturation via precursor partial pressures and working near equilibrium conditions, growth can be preferentially sustained on only the semiconductor surfaces. ${ }^{10}$ Under proper growth conditions, selectivity between semiconductors and the oxide surface can be sufficiently high to completely preclude nucleation on the oxide surface and permit epitaxial growth through even three-dimensional oxide templates. ${ }^{9}$

Selective chemical vapor deposition (CVD) of other materials using other mechanisms is also possible. For example, selective silicon homoepitaxy can be favored over growth on patterned $\mathrm{SiO}_{2}$ surfaces by using hydrogen's preferential etching of strained silicon-silicon ( $\mathrm{Si}-$ $\mathrm{Si}$ ) bonds. By adjusting the $\mathrm{SiH}_{4}$ to $\mathrm{H}_{2}$ delivery ratio, nucleation can be prevented on nonepitaxial surfaces, like $\mathrm{SiO}_{2}$, where the $\mathrm{Si}-\mathrm{Si}$ bonds are more strained. ${ }^{11,12} \mathrm{In}$ CVD of metal films, surface reactivity is used to achieve selectivity. Selective deposition of tungsten films from $\mathrm{WF}_{6}$ is possible because semiconductor surfaces decompose the precursor molecule to initiate nucleation while oxide surfaces are unreactive toward the precursor. ${ }^{13,14}$ Patterning of metal catalysts is used for the selective deposition of semiconductor nanowires ${ }^{15}$ and carbon nanotubes. ${ }^{16}$ Focused ion beams have also been used to "direct-write" epitaxial patterns of III-V semiconductors on crystalline substrates. ${ }^{17}$

Selectivity is less common in physical vapor deposition (PVD) like molecular beam epitaxy (MBE) because elemental precursor sources ( $\mathrm{Ga}, \mathrm{Al}$, As, etc.,) have higher sticking coefficients than their organometallic precursor analogues $\left[\mathrm{Ga}\left(\mathrm{CH}_{3}\right)_{3}, \mathrm{Al}\left(\mathrm{CH}_{3}\right)_{3}, \mathrm{AsH}_{3}\right.$, etc., $]$, minimizing the differences in surface interactions. The most studied PVD process has been the selective area growth of GaAs by MBE at high growth temperatures and low gallium fluxes. ${ }^{18,19}$ Several approaches have been introduced to improve the reliability and growth rates of this selective area MBE process, including the use of activated species, ${ }^{20}$ focused ion beams, ${ }^{21}$ and precursor flux pulsing. ${ }^{22}$ Selectivity with other PVD techniques, like sputtering, has been reported, but these typically require a narrow process window of deposition rate and substrate temperature. ${ }^{23}$

In this paper, we describe a new MBE process for the $\mathrm{SAE}$ growth of $\mathrm{MgO}$ epilayers on gallium nitride surfaces. The ability to grow oxide epilayers over selective areas while retaining high crystalline quality is significant as the patterning of epitaxial oxide films often requires a hard-mask approach involving multiple processing steps. ${ }^{24}$ In general, the epitaxial growth of oxides on wide-gap semiconductors has been studied in detail by us ${ }^{25-31}$ and others ${ }^{32-38}$ and has contemporary importance in the development of new high frequency and high power microelectronic devices for wireless communication and power conditioning. ${ }^{39-41}$ This new processing technique uses surface chemistry patterning to direct the selective growth of $\mathrm{MgO}$ epilayers. A simple change in the GaN's surface chemistry to Cl-termination is found to prevent sticking of the $\mathrm{Mg}$ precursor and inhibit growth. Various surface characterization techniques are applied to further understand the selective growth mechanisms, and lateral patterns of $\mathrm{MgO}$ epilayers with micrometer resolution are demonstrated.

\section{EXPERIMENTAL PROCEDURES}

GaN epilayers (1.2 $\mu \mathrm{m}$ thick) deposited via coldwalled MOCVD on (0001) sapphire substrates using an AlN buffer layer were used as growth surfaces for MBE of $\mathrm{MgO}$. Using a $\mathrm{N}_{2}$ diluent gas with triethylgallium, trimethylaluminum, and ammonia precursors, $\mathrm{GaN}$ was MOCVD grown under mass transport limited conditions. $^{42,43}$ Final GaN growth surfaces had an (0001) Ga-face polarity orientation.

To control surface chemistry, GaN films were treated with either a concentrated $12 \mathrm{M} \mathrm{HCl}$ dip for $5 \mathrm{~min}$ (" $\mathrm{HCl}$ treatment") or a 1:99 (by volume) ratio of $32 \mathrm{M} \mathrm{HF:DI}$ (deionized) water ("HF treatment") for $5 \mathrm{~min}$. Treatment times as short as $1 \mathrm{~min}$ appeared to be equally effective, and $\mathrm{HCl}$ treatments without $\mathrm{HF}$ treatments also prevented film growth. For selective area patterning, the entire surface received an "HF treatment," a patterned polymer mask was lithographically applied, and the remaining exposed surface was given an " $\mathrm{HCl}$ treatment." The polymer mask was then removed by sonicating in acetone for 2-5 $\mathrm{min}$, and the GaN film was loaded into our oxide MBE.

All GaN substrates were thermally desorbed at $500{ }^{\circ} \mathrm{C}$ for $\geq 10 \mathrm{~min}$ in ultra high vacuum (UHV) at a pressure $<5$ $\times 10^{-8}$ Torr to further remove contaminants. A PerkinElmer 435 MBE system (PerkinElmer Inc., Waltham, Massachusetts) was used to deposit $\mathrm{MgO}$ epilayers. ${ }^{28,29}$ 
Magnesium metal (99.98\% purity filings from Alfa Aesar, Haverhill, Massachusetts) was sublimed from a PerkinElmer effusion cell containing a pyrolytic BN crucible. The metal flux was calibrated with a quartz crystal microbalance (Inficon XTM/2 Deposition Monitor, Inficon, Bad Ragaz, Switzerland) prior to substrate introduction via a loadlock. Most growths were conducted at relatively low metal fluxes of $\sim 5 \times 10^{13}$ atoms $\mathrm{cm}^{-2} / \mathrm{s}^{-1}$, which corresponds to about 0.05 monolayers (MLs) of $\mathrm{Mg}$ per second. This $\mathrm{Mg}$ flux requires an effusion cell temperature between 340 and $360{ }^{\circ} \mathrm{C}$ depending on the crucible charge. Ultra-high purity oxygen was supplied as the oxidant via a $45 \mathrm{~cm}$ long stainless steel tube aimed at the substrate. The oxygen delivery rate was regulated with a UHV leak valve and monitored with an ion gauge attached to the opposing chamber wall. The desired oxygen partial pressure was set prior to growth, and growth was then initiated by the opening of the $\mathrm{Mg}$ effusion cell. Due to $\mathrm{O}_{2}$ gettering at the walls, the oxygen flux was continuously adjusted during the initial $5 \mathrm{~min}$ of growth until a steadystate pressure was achieved. Substrates were mechanically fastened to a molybdenum transfer puck using molybdenum clips. The molybdenum puck was radiation-heated by using a Ta filament. Reflection high energy electron diffraction (RHEED) patterns were collected in situ with a PerkinElmer $\Phi$ 20-330 analog HEED gun system projected on a phosphor screen and digitally captured with a k-Space acquisition system (kSA 400, K-Space Associates, Inc., Dexter, Michigan). Sample temperature was monitored with a Raytek IR pyrometer (Marathon Series) focused on the molybdenum puck.

$\mathrm{MgO}$ film thickness was measured ex situ with a Dektak profilometer (Bruker Nano Surfaces, Tucson, Arizona) using the step edge created by the molybdenum fastening clips. X-ray diffraction (XRD) patterns were collected with a Bruker AXS D-5000 diffractometer equipped with a High-Star area detector (Bruker AXS, Madison, Wisconsin). Images of the static contact angle for water droplets on various GaN surfaces were captured with a Ramé-Hart goniometer (RAME-HART, Succasunna, New Jersey) and analyzed with the DROPimage CA software. Patterned epilayers were imaged with a Hitachi S3200N scanning electron microscope (SEM; Hitachi, Tokyo, Japan) equipped with an Oxford energy dispersive x-ray spectrometer (EDS; Oxford Instruments, Abingdon, UK) for elemental analysis.

X-ray photoelectron spectroscopy (XPS) measurements were carried out in a surface analysis chamber (base pressure $<1.0 \times 10^{-10}$ Torr) using a VG hemispherical spectrometer and a dual-anode $\mathrm{x}$-ray source. $\mathrm{Al} \mathrm{K}_{\alpha}$ radiation $(1486.6 \mathrm{eV})$ was used for this experiment. The spectrometer was operated at a constant pass energy of $50 \mathrm{eV}$ for survey scans, and $20 \mathrm{eV}$ for detailed core level scans. XPS data were analyzed using IGOR Pro (Wavemetrics), and peak fitting, where applied, was accomplished using Voigt peak shapes.

\section{RESULTS AND DISCUSSION}

\section{A. Demonstration of SAE}

In Fig. 1, we demonstrate the general process for SAE of $\mathrm{MgO}$ epilayers on Ga-face (0001) GaN surfaces. First, the entire $\mathrm{GaN}$ surface is treated with 1:99 $\mathrm{HF}: \mathrm{H}_{2} \mathrm{O}$ (5 $\mathrm{min}$ ), and then the regions where deposition is desired are masked [here with a green lacquer for visibility, Fig. 1(a)]. Next, the sample is immersed in concentrated $\mathrm{HCl}$ for $5 \mathrm{~min}$ and rinsed with DI water [Fig. 1(b)]. The mask is then removed by sonication in acetone, leaving no visible pattern on the surface [Fig. 1(c)]. Finally, an $\mathrm{MgO}$ film is deposited by $\mathrm{MBE}$ at high growth temperatures (here at $400{ }^{\circ} \mathrm{C}$ ) and low deposition rates [here at $6 \times 10^{13} \mathrm{Mg}$ atoms $\mathrm{cm}^{-2} / \mathrm{s}^{-1}, 3 \times 10^{-6}$ Torr $\left.\mathrm{O}_{2}, \sim 0.4 \mathrm{~nm} / \mathrm{min}\right]$. The $\mathrm{MgO}$ film selectively grows where the GaN surface has not been exposed to $\mathrm{HCl}$. In the following sections, we show that this prevention of film growth is due to a surface layer of $\mathrm{Cl}$ adatoms. The film seen in Fig. 1(d) is $\sim 75 \mathrm{~nm}$ thick ( $3 \mathrm{~h}$ of growth). Under these conditions and extended deposition time, some lateral growth from the non- $\mathrm{HCl}$ treated area is observed. This is consistent with other SAE processes where epitaxial lateral overgrowth occurs. ${ }^{44}$

\section{B. Evaluation of SAE process window}

To evaluate the SAE process window, $\mathrm{MgO}$ films were deposited on " $\mathrm{HCl}$ treated" and "HF treated" $\mathrm{GaN}$ surfaces over a range of substrate temperatures $\left(200-450{ }^{\circ} \mathrm{C}\right)$ at a constant $\mathrm{Mg}$ flux $\left[5 \times 10^{13}\right.$ atoms $\left./\left(\mathrm{cm}^{-2} / \mathrm{s}^{-1}\right)\right]$ and oxygen partial pressure $\left(6 \times 10^{-6}\right.$ Torr $)$. All depositions were conducted for at least $45 \mathrm{~min}$. Deposition rates derived from profilometry measurements of the film's final thickness are reported in Fig. 2. Immediately evident is a lower net deposition rate for all $\mathrm{HCl}$ treated $\mathrm{GaN}$ surfaces under the conditions explored. As discussed in theoretical work by Geneste et al. $^{45,46}$ and our own experimental work, ${ }^{29}$ adsorption-controlled growth of $\mathrm{MgO}$ is not dependent on a single component. Depending on the growth conditions, the Mg flux, the $\mathrm{O}_{2}$ flux, or both can be used to regulate film growth rates. The relative difference in incident $\mathrm{Mg}$ flux and $\mathrm{Mg}$ re-evaporation rate helps to delineate these different regimes. Using the equilibrium vapor pressure of $\mathrm{Mg}$ at $200{ }^{\circ} \mathrm{C}$, we estimate a $\mathrm{Mg}$ re-evaporation rate from the surface of $\sim 10^{13}$ atoms $\mathrm{cm}^{-2} / \mathrm{s}^{-1}$ using the HertzKundsen equation. The re-evaporation rate rises to $\sim 10^{15}$ atoms $\mathrm{cm}^{-2} / \mathrm{s}^{-1}$ at $250{ }^{\circ} \mathrm{C} .{ }^{29}$ Because these experiments use an incident $\mathrm{Mg}$ flux of $\sim 5 \times 10^{13}$ atoms $\mathrm{cm}^{-2} / \mathrm{s}^{-1}$, Mg reevaporation fluxes exceed incident fluxes over most of the growth conditions explored in Fig. 2. Under these growth conditions, $\mathrm{MgO}$ growth rate depends on both the $\mathrm{Mg}$ flux and the $\mathrm{O}_{2}$ flux. ${ }^{29}$

Regardless of surface chemistry, $\mathrm{MgO}$ growth with low Mg fluxes will eventually be kinetically prohibited 


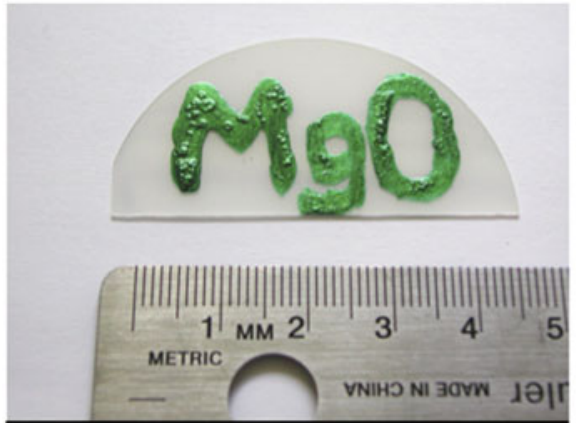

(a) Mask area to pattern

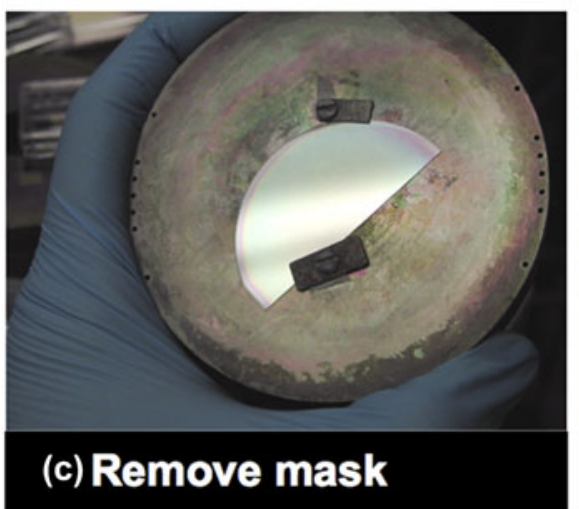

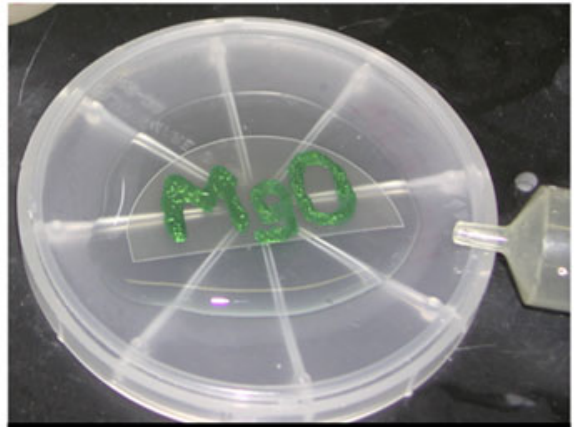

(b) Treat with $\mathrm{HCl}$

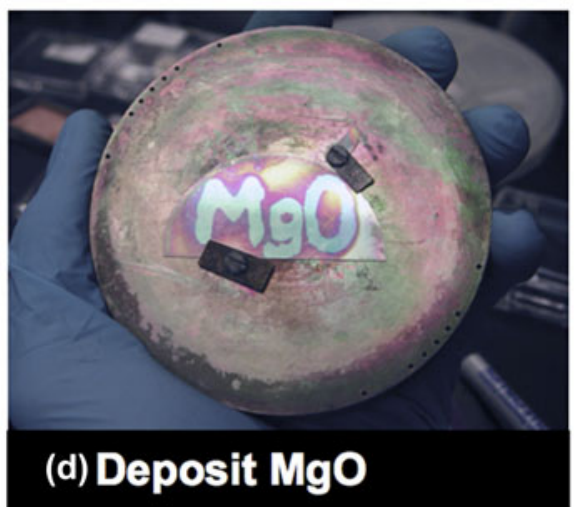

FIG. 1. Demonstration of MgO SAE process: (a) mask region for epitaxial growth with polymer, (b) expose patterned wafer to concentrated hydrochloric acid, (c) remove mask with acetone, and (d) selectively grow $\mathrm{MgO}$ by $\mathrm{MBE}$.

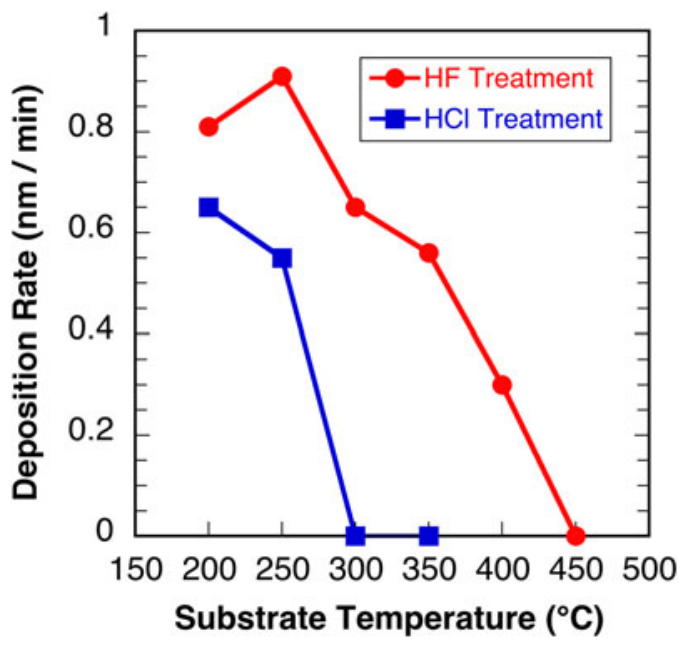

FIG. 2. Growth rates for $\mathrm{MgO}$ on $\mathrm{GaN}$ surfaces undergoing either an $\mathrm{HF}$ (red circles) or $\mathrm{HCl}$ (blue squares) treatment prior to film deposition.

by high $\mathrm{Mg}$ re-evaporation rates at high substrate temperatures. This critical temperature is $\sim 450{ }^{\circ} \mathrm{C}$ for the $\mathrm{HF}$ treated $\mathrm{GaN}$ surface but is $150{ }^{\circ} \mathrm{C}$ lower $\left(300{ }^{\circ} \mathrm{C}\right)$ for the $\mathrm{HCl}$ treated surface. This reduction in critical temperature suggests a difference in the sticking coefficients for each surface. The optimal SAE growth conditions occur within the temperature range that provides the largest contrast in growth rates on the two surfaces. For the $\mathrm{Mg}$ and $\mathrm{O}_{2}$ fluxes studied here, this optimal SAE temperature range is between 300 and $350{ }^{\circ} \mathrm{C}$.

\section{Crystallinity of SAE MgO films on GaN}

To evaluate the crystalline quality of these $\mathrm{MgO}$ films, we use the optimal parameters found in Sec. III. B to selectively deposit $\mathrm{MgO}$ films onto a $\mathrm{GaN}$ surface that is half exposed to an $\mathrm{HCl}$ treatment and half exposed to an $\mathrm{HF}$ treatment. Optimal growth conditions of $350{ }^{\circ} \mathrm{C}, 5 \times$ $10^{13} \mathrm{Mg}$ atoms $\mathrm{cm}^{-2} / \mathrm{s}^{-1}$, and oxygen partial pressures of $3 \times 10^{-6}$ are used. As shown in Fig. 3(a), the film is visibly detectable on the HF treated side (right) but no film is visible on the $\mathrm{HF}+\mathrm{HCl}$ treated side (left). Films on the HF treated GaN surface measure $60 \mathrm{~nm}$ in thickness (measured using profilometry of the step edge created by blocked deposition from the "clip" holding the substrate to the transfer puck). In-plane XRD patterns are collected from both the $\mathrm{HCl}$ treated and $\mathrm{HF}$ treated regions and reported in Figs. 3(b) and 3(c), respectively. $\mathrm{MgO}$ deposited on the HF treated surface shows only evidence of the 111 in-plane reflection (observed as a single spot on our XRD's area detector) indicative of (111) $\mathrm{MgO} \|(0001) \mathrm{GaN}$ epitaxy and consistent with our prior reports. ${ }^{26,28}$ In the $\mathrm{HCl}$ treated region, no diffraction peaks for $\mathrm{MgO}$ are detected. Because $\mathrm{MgO}$ deposition 


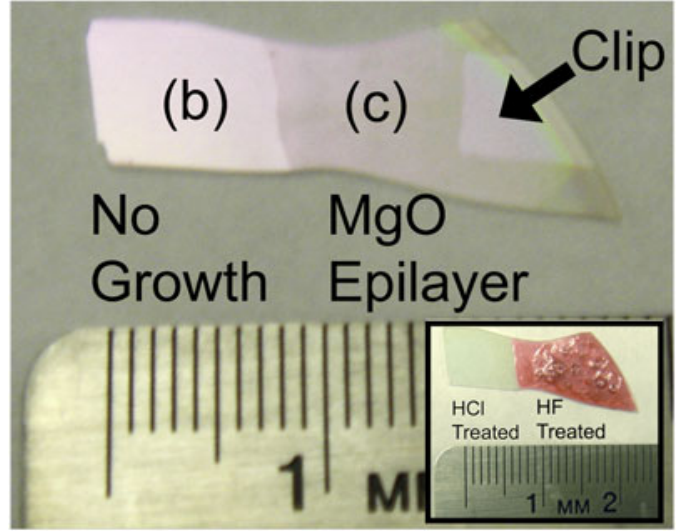

(a)

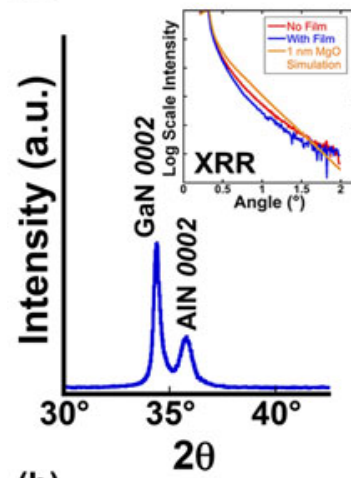

(b)

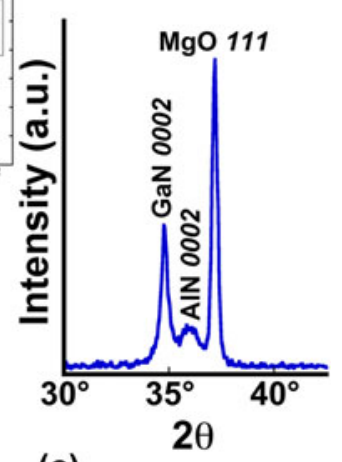

(c)

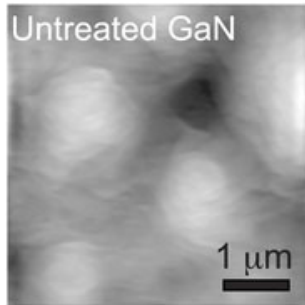

(a)

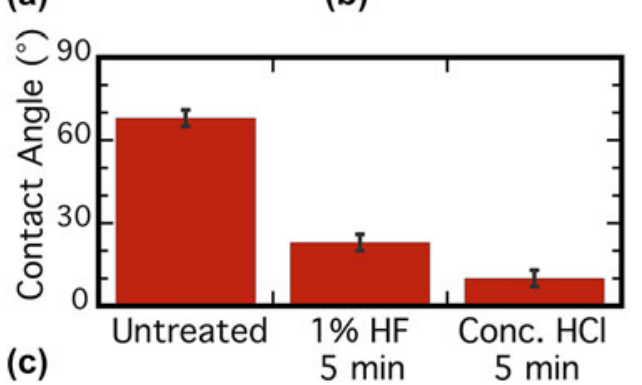

FIG. 4. AFM images of GaN surfaces (a) as-grown and (b) after " $\mathrm{HCl}$ treatment." (c) Water contact angle on GaN surfaces after various surface treatments.

representative atomic force microscope (AFM) scans from a comprehensive study of the surface morphology of $\mathrm{GaN}$ under a variety of treatments. This study revealed no noticeable difference in the surface morphology after any chemical treatment. For example, in Fig. 4, both treated and untreated $5 \mu \mathrm{m} \times 5 \mu \mathrm{m}$ AFM scans have an average RMS roughness of $0.67 \mathrm{~nm}$. Based on these results, we eliminate the surface morphology as a root cause for the observed difference in the sticking coefficient.

Next, we macroscopically assessed surface energy using water contact angle measurements. These results are summarized in Fig. 4(c). As grown, MOCVD GaN epilayers have a contact angle of $\sim 68^{\circ}$, likely indicative of hydrophobic carbon contamination. Treatment in a $1 \%$ HF solution for $5 \mathrm{~min}$ lowers the contact angle to $\sim 23^{\circ}$. In contrast, exposure of the as-grown $\mathrm{GaN}$ surface to concentrated $\mathrm{HCl}$ for $5 \mathrm{~min}$ provides an even lower contact angle of $\sim 10^{\circ}$. Repetition of this experiment provided similar results, suggesting a clear change in the surface energy between $\mathrm{HF}$ and $\mathrm{HCl}$ treated $\mathrm{GaN}$ surfaces. Because no change in the surface morphology is detected, we conclude that this change in surface energy is a result of a change in surface chemistry.

XPS was used to probe the surface's chemical composition after various chemical treatments. Survey scans, presented in Fig. 5(a), show no significant differences in the chemistry of an "HF treated" and " $\mathrm{HCl}$ treated" $\mathrm{GaN}$ surface. However, high resolution XPS scans across the Cl $2 p$ shell's binding energy reveal clear photoemission from the "HCl treated" surface [Fig. 5(b)]. Integration of this peak indicates the surface concentration of $\mathrm{Cl}$ to be equal to about $1 \mathrm{ML}$ of adatoms. For "HF treated" GaN 
surfaces, the $\mathrm{Cl}$ concentration is near zero, with any detectable levels likely coming from cross-contamination during our etch process. These results are consistent with prior findings. Wet chemical etches with $\mathrm{HF}$ and $\mathrm{HCl}$ are known to help in removing surface oxides and carbon contaminants with only minor changes to the surface morphology. Residual $\mathrm{F}$ and $\mathrm{Cl}$ atoms have been previously detected on GaN by surface spectroscopy after $\mathrm{HF}$ and $\mathrm{HCl}$ treatments, respectively. ${ }^{47-50}$

As a complementary control experiment, we also considered treatment in another strong acid, $\mathrm{HNO}_{3}$. $\mathrm{GaN}$ surfaces exposed for $5 \mathrm{~min}$ to concentrated $\mathrm{HNO}_{3}$ $(16 \mathrm{M})$ exhibited identical deposition rates to HF treated GaN surfaces. This control experiment helps to eliminate acidic protons, which are undetectable by XPS, as a source for deposition prevention, leaving passivation via surface chlorination as the most likely mechanism.

Based on these findings, we propose that a $\mathrm{ML}$ of $\mathrm{Cl}$ adatoms is the source of the observed changes to the sticking coefficient during $\mathrm{MgO}$ growth. At this point, we are unable to fully clarify the binding state of this $\mathrm{Cl} \mathrm{ML}$ on the GaN surface. While we expect GaN surfaces to be Ga terminated ${ }^{51,52}$ and $\mathrm{GaCl}_{2}$ to be a thermodynamically favored product, ${ }^{53}$ XPS scans of the Ga $3 d$ photoemission line have been inconclusive in revealing a clear $\mathrm{Ga}-\mathrm{Cl}$ bond. A small shoulder at high binding energies is consistently observed for many GaN surfaces. This shoulder could be attributed to either surface oxygen or surface chlorine and is difficult to differentiate. $\mathrm{Mg}$ is also known to readily react with $\mathrm{Cl}$ to form stable $\mathrm{MgCl}_{2}$ surfaces. ${ }^{54}$ Thus, the surface-bound $\mathrm{Cl}$ atoms may also react with the incident $\mathrm{Mg}$ flux to form a $\mathrm{MgCl}_{x}$ surface layer. Regardless of its exact chemistry, it is apparent that the surface-bound $\mathrm{Cl}$ is reducing the surface adsorption of the $\mathrm{Mg}$ and/or $\mathrm{O}_{2}$ precursor species. This reduced surface resonance time likely precludes the dissociation of molecular $\mathrm{O}_{2}$, which is known to be a rate limiting step in reactive $\mathrm{MgO}$ film growth. ${ }^{45,46}$

\section{E. Retainment of $\mathrm{Cl}$ adatoms on the surface of MgO epilayers}

Our prior work ${ }^{25,26}$ using hydroxyls as surfactants to energetically stabilize the (111) surface of $\mathrm{MgO}$ epilayers during film growth made us curious as to whether the $\mathrm{Cl}$ adatoms could show similar surfactant behavior. Growth of atomically smooth (111) $\mathrm{MgO}$ epilayers is essential for good insulating performance and so has great technological relevance. ${ }^{25}$ Several parallels could be made between the hydroxide and chloride behaviors including the observation that hydroxylated (111) $\mathrm{MgO}$ epilayers have a slower growth rate than nonhydroxylated epilayers. In this study, we used high $\mathrm{Mg}$ and $\mathrm{O}_{2}$ fluxes to force growth on the "HCl treated" surfaces. GaN surfaces with both an "HCl treatment" and "HF treatment" were simultaneously exposed to identical growth conditions $\left[475{ }^{\circ} \mathrm{C}\right.$ growth temperature, $\mathrm{Mg}$ flux of $4 \times 10^{14}$ atoms/ $\left(\mathrm{cm}^{-2} / \mathrm{s}^{-1}\right)$, and $3 \times 10^{-6}$ Torr $\left.\mathrm{O}_{2}\right]$ and their surface chemistries were studied by XPS and RHEED. Films were grown until the $\mathrm{MgO}$ epilayers reached a nominal thickness of $\sim 50 \mathrm{~nm}$ on the HF treated GaN surface.

The XPS survey scans presented in Fig. 6(a) indicate no detectable emission lines for the underlying $\mathrm{GaN}$ substrate for either of the $\mathrm{MgO} \| \mathrm{GaN}$ structures. This absence of substrate emission indicates that the $\mathrm{MgO}$ films on both surfaces are fully coalesced. Surprisingly, $\mathrm{MgO}$ films grown on " $\mathrm{HCl}$ treated" GaN surfaces still show detectable levels of $\mathrm{Cl}$. This $\mathrm{Cl}$ emission is verified in the highresolution XPS scan shown in Fig. 6(b). Because no additional $\mathrm{Cl}$ is provided during growth and no $\mathrm{Cl}$ signal is detected in the HF treated sample, we conclude that the original $\mathrm{ML}$ of surface-bound $\mathrm{Cl}$ takes part in the $\mathrm{MgO}$ growth process. During growth, this $\mathrm{Cl}$ ML must remain, at least partially, on the $\mathrm{MgO}$ surface, similar to the behavior of other film growth "surfactants." 25,55

The use of $\mathrm{Cl}$ as a surfactant for (111) $\mathrm{MgO}$ surfaces is consistent with prior observations. Koranyi et al. have
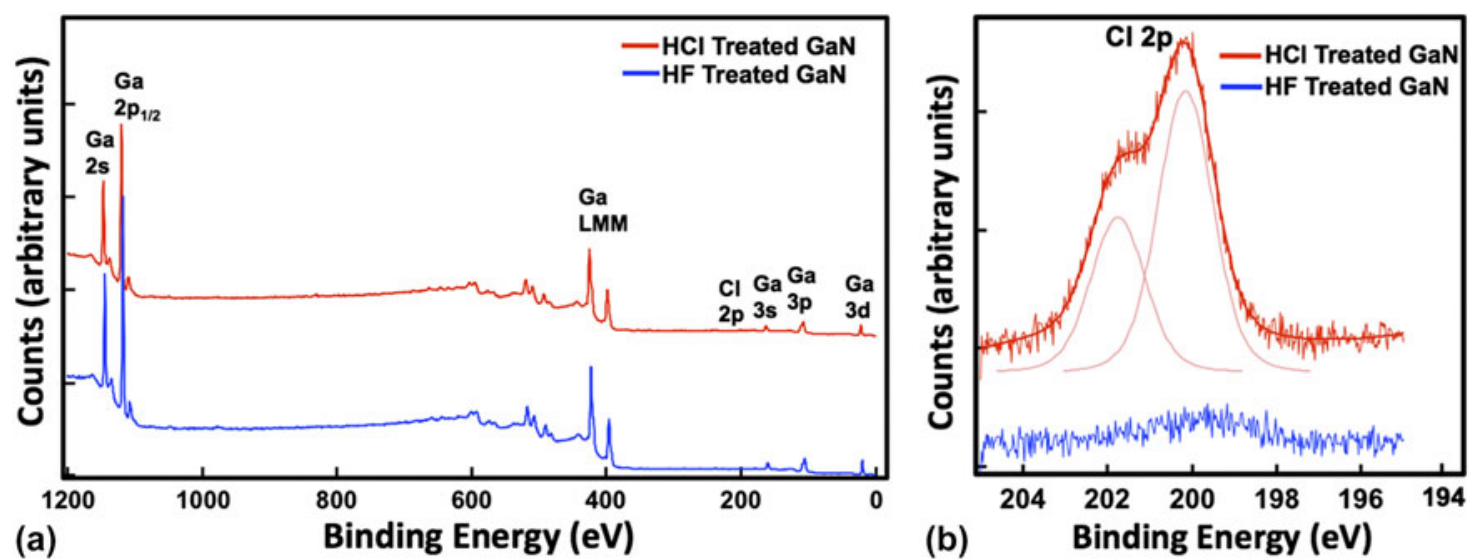

FIG. 5. XPS spectra of GaN surfaces exposed to either an "HCl treatment" (red) or "HF treatment" (blue): (a) survey scans and (b) high resolution scans of the $\mathrm{Cl} 2 p$ photoemission lines. Spectra are offset for clarity. 


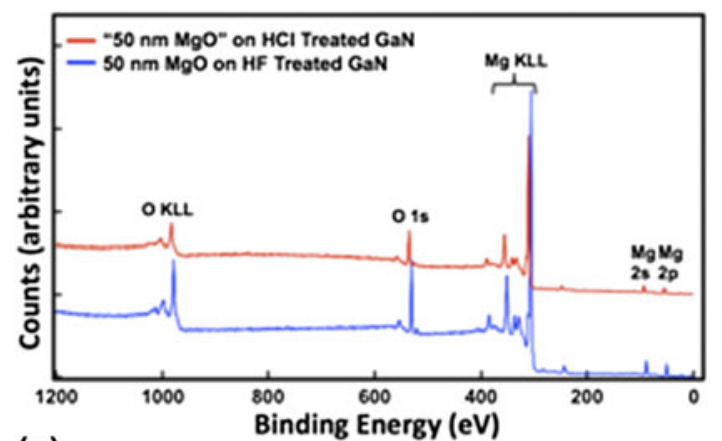

(a)

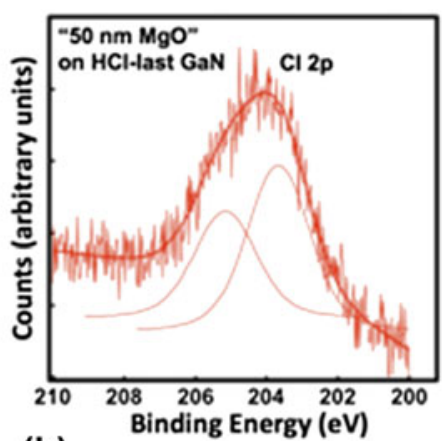

(b)

FIG. 6. XPS spectra collected from nominally $50 \mathrm{~nm}$ thick $\mathrm{MgO}$ epilayers grown on "HCl treated" (red) and "HF treated" (blue) GaN surfaces under "high" Mg flux conditions: survey spectra and high-resolution scan of $\mathrm{Cl} 2 p$ photoemission line. Spectra are offset for clarity.

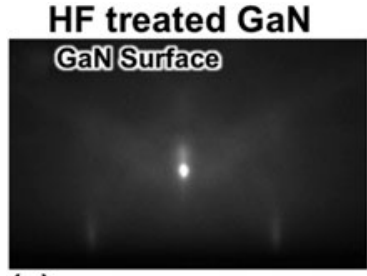

(a)

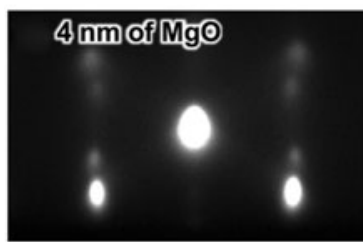

(b)

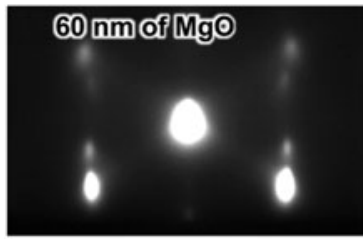

(c)

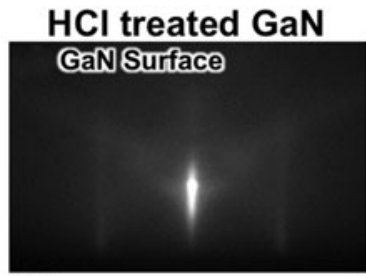

(d)

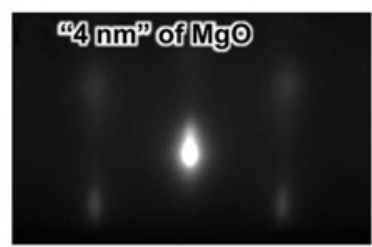

(e)

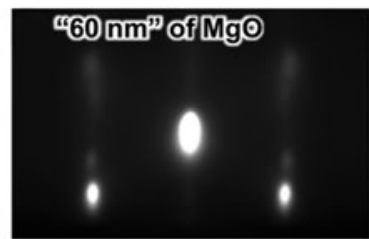

(f)

FIG. 7. Images of RHEED patterns during high flux growth on HFtreated $(\mathrm{a}-\mathrm{c})$ and $\mathrm{HCl}$-treated $(\mathrm{d}-\mathrm{f}) \mathrm{GaN}$ surfaces. Growth conditions on both surfaces are identical. Images are collected at the same fluxtime doses and thicknesses are referenced to the calibrated $\mathrm{MgO}$ thickness for growth on HF-treated GaN.

reported $\mathrm{Cl}$ to be labile and show preferential surface residence when growing $\mathrm{Mg}$ metal on top of $\mathrm{MgCl}_{2}$ crystals. ${ }^{54}$ Presumably, this is driven by a reduction of free energy that accompanies a $\mathrm{MgCl}_{2}$-like skin. To accurately substantiate Cl's surfactant ability, detailed ab initio studies are needed to compare the stability of a chlorinated (111) $\mathrm{MgO}$ surface to modified or unmodified (100) $\mathrm{MgO}$ surfaces. While this is beyond the scope of the current work, a simple calculation using bulk thermodynamic data ${ }^{53}$ shows that $\mathrm{MgCl}_{2}\left(\Delta G_{\text {formation }}=\right.$ $-530 \mathrm{~kJ} / \mathrm{mol})$ is more stable than $\mathrm{MgO}\left(\Delta G_{\text {formation }}=\right.$ $-525 \mathrm{~kJ} / \mathrm{mol}$ ) at the growth temperatures explored, providing some credence to the $\mathrm{Cl}$ surfactant hypothesis.

We have also used in situ RHEED analysis to study film growth under these "high" Mg flux conditions. Images of RHEED patterns collected for $\mathrm{MgO}$ films grown on $\mathrm{HCl}$ treated and HF-treated $\mathrm{GaN}$ at high flux rates are shown in Fig. 7. Here, the RHEED patterns were collected for equivalent flux-time doses. $\mathrm{MgO}$ film growth is retarded on HCl-treated $\mathrm{GaN}$ as evidenced by less charging in the RHEED patterns. Both RHEED signals become "spotty" diffraction patterns almost immediately and no intensity oscillations are detected. These observations indicate the immediate formation of a rough growth surface consistent with Volmer-Weber (island) film growth. These results imply that pyramidal $\mathrm{MgO}$ crystals with (100) facets nucleate and grow on the (0001) GaN surface for both $\mathrm{HF}$ - and $\mathrm{HCl}$-treated $\mathrm{GaN}$ at high growth rates, consistent with the surfactant-less equilibrium habit of $\mathrm{MgO}$ epilayers grown in vacuum. ${ }^{26,27}$

While discouraging, these results do not completely preclude Cl's utility as a surfactant. A continual supply of $\mathrm{Cl}$ is likely needed to maintain sufficient surface concentrations to influence growth mode. We see a similar need to provide a constant $\mathrm{H}_{2} \mathrm{O}$ surfactant flux when growing smooth, - $\mathrm{OH}$ terminated (111) $\mathrm{MgO}$ epilayers on $\mathrm{GaN}^{25}$ If the $\mathrm{H}_{2} \mathrm{O}$ flux is removed at any point during film growth, the surfactant effect is lost and a rapid transition from $2 \mathrm{D}$ to $3 \mathrm{D}$ growth mode occurs. Indeed, the concentrations of $\mathrm{Cl}$ are noticeably lower on the surface of the thick $\mathrm{MgO}$ films [Fig. 6(b)] than on the surface of the starting " $\mathrm{HCl}$ treated" $\mathrm{GaN}$ [Fig. 5(b)], suggesting that a $\mathrm{Cl}_{2}$ supply in the MBE growth environment is needed to achieve the surfactant effect.

\section{F. Implementation of SAE MgO on GaN for lateral patterning}

Finally, we report on pattern resolution for the $\mathrm{MgO}$ SAE process. Here, we have used standard photolithographic micropatterning techniques to selectively chlorinate the $\mathrm{GaN}$ surface. $\mathrm{MgO}$ films with a thickness of $\sim 55 \mathrm{~nm}$ were grown selectively via $\mathrm{MBE}$ on these chlorinated patterns. Representative SEM images of the 
final patterned films grown from these surfaces are shown in Fig. 8. Note that $\mathrm{MgO}$ patterns appear bright in the SEM images due to sample charging. This compositional identification is further confirmed by an EDS line scan analysis shown in Fig. 9. Because film growth was conducted outside of a cleanroom, dust particles are present. All patterns retain sharp, well-defined edges,

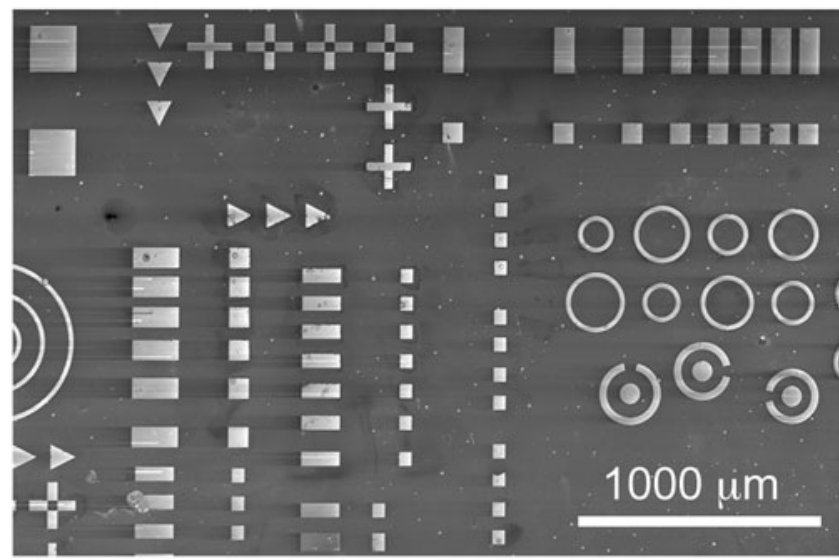

(a)

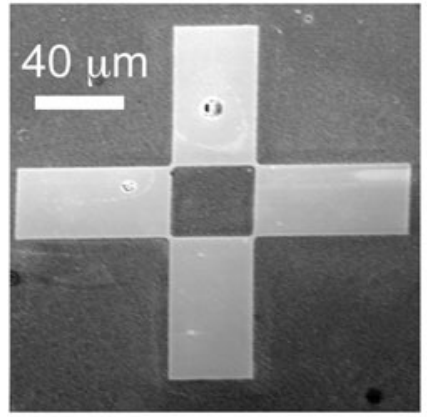

(b)

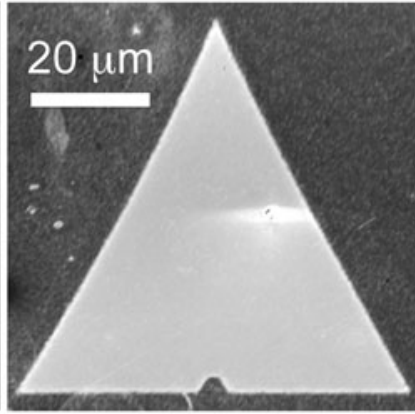

(c)

FIG. 8. (a-c) SEM images of MgO SAE on GaN using photolithographic patterning to define regions of surface modification. White areas are $\mathrm{MgO}$ epilayers while dark areas are the $\mathrm{GaN}$ surface.

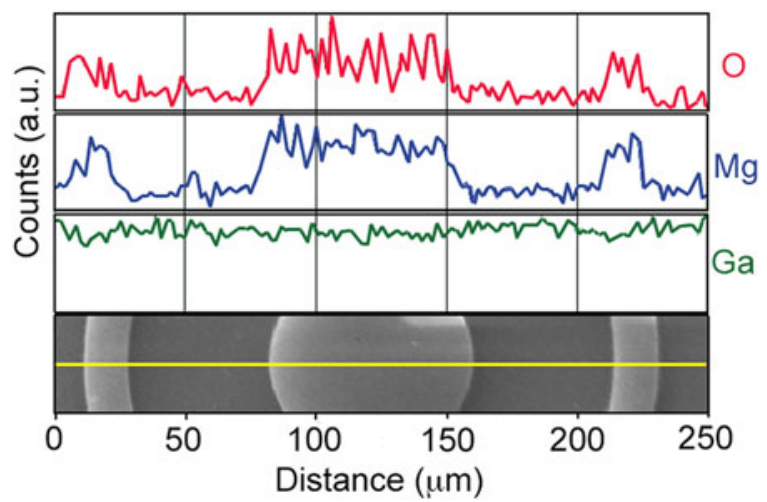

FIG. 9. EDS line scans of the $\mathrm{O}$ and $\mathrm{Mg} \mathrm{K}$-shells and $\mathrm{Ga}$ L-shell characteristic x-rays across a $\mathrm{MgO} \mathrm{SAE}$ pattern. The corresponding SEM image from which the EDS line scans were collected is shown at the bottom. and features as small as $3 \mu \mathrm{m}$ are easily replicated in the $\mathrm{MgO}$ epilayers, suggesting that even finer resolution is likely possible.

\section{CONCLUSIONS}

A new approach for the selective area epitaxy of $\mathrm{MgO}$ films on $\mathrm{GaN}$ surfaces is presented. Immersion of a $\mathrm{GaN}$ surface into an $\mathrm{HCl}$ solution is found to prevent the deposition of $\mathrm{MgO}$ films under certain $\mathrm{MBE}$ growth conditions (high substrate temperatures and low incident $\mathrm{Mg}$ fluxes). A $\mathrm{ML}$ of $\mathrm{Cl}$ adatoms was the only detectable difference in the surface structure between the " $\mathrm{HCl}$ treated" GaN surfaces that blocked deposition and control surfaces that allowed $\mathrm{MgO}$ deposition. Based on XPS studies of the surface chemistry during $\mathrm{MgO}$ film growth in combination with prior studies of $\mathrm{MgO}$ surface adsorption kinetics, we conclude that the adsorbed chlorine ML forms an energetically stable (0001) GaN surface with a reduced sticking coefficient for $\mathrm{Mg}$ and $\mathrm{O}_{2}$ precursors. When this chlorine passivation layer is applied in a lateral pattern to a $\mathrm{GaN}$ surface, epitaxial $\mathrm{MgO}$ films preferentially nucleate and grow in the unchlorinated regions. Lateral patterning of $\mathrm{MgO}$ epilayers with micrometer feature sizes is demonstrated, although even better resolution is likely possible. Because few processes exist for the selective deposition of oxide materials, this technique has important ramifications for simplifying microelectronics processing, especially in the quickly growing industries of solid-state lighting, microwave electronics, and power conditioning.

\section{ACKNOWLEDGMENTS}

The authors acknowledge funding from the ONR MURI project Epitaxial Multifunctional Materials and Applications (2004-0779), the NSF Graduate Fellowship program, and Georgia Tech startup funds. Sandia National Laboratories is a multi-program laboratory managed and operated by Sandia Corporation, a wholly owned subsidiary of Lockheed Martin Corporation, for the U.S. Department of Energy's National Nuclear Security Administration under contract DE-AC0494A185000. We also thank Jan Genzer for access to his contact angle goniometer and data analysis software.

\section{REFERENCES}

1. H. Heinecke, A. Brauers, F. Grafahrend, C. Plass, N. Putz, K. Werner, M. Weyers, H. Luth, and P. Balk: Selective growth of GaAs in the MOMBE and MOCVD systems. J. Cryst. Growth 77(1-3), 303 (1986)

2. T. Fukui, S. Ando, Y. Tokura, and T. Toriyama: GaAs tetrahedral quantum dot structures fabricated using selective area metalorganic chemical vapor-deposition. Appl. Phys. Lett. 58(18), 2018 (1991). 
3. K.Y. Zang and S.J. Chua: GaN based nanorod light emitting diodes by selective area epitaxy. Phys. Status Solidi C 7(7-8), 2236 (2010).

4. M.T. Bjork, H. Schmid, C.M. Breslin, L. Gignac, and H. Riel: InAs nanowire growth on oxide-masked $\langle 111\rangle$ silicon. J. Cryst. Growth 344(1), 31 (2012).

5. Y. Yamazaki, J.H. Chang, M.W. Cho, T. Sekiguchi, and T. Yao: Selective-area growth of $\mathrm{ZnSe}$ on patterned $\mathrm{GaAs}(001)$ substrates by molecular beam epitaxy. J. Cryst. Growth 214, 202 (2000).

6. J.M. Hartmann, F. Bertin, G. Rolland, F. Laugler, and M.N. Semeria: Selective epitaxial growth of $\mathrm{Si}$ and $\mathrm{SiGe}$ for metal oxide semiconductor transistors. J. Cryst. Growth 259(4), 419 (2003).

7. G. Levitin and D.W. Hess: Surface reactions in microelectronics process technology. In Annual Review of Chemical and Biomolecular Engineering, Vol. 2, J.M. Prausnitz ed.; Annual Reviews: Palo Alto, CA, 2011; p. 299.

8. R. Azoulay, N. Bouadma, J.C. Bouley, and L. Dugrand: Selective MOCVD epitaxy for optoelectronic devices. J. Cryst. Growth $\mathbf{5 5}$ (1), 229 (1981).

9. E.C. Nelson, N.L. Dias, K.P. Bassett, S.N. Dunham, V. Verma, M. Miyake, P. Wiltzius, J.A. Rogers, J.J. Coleman, X.L. Li, and P.V. Braun: Epitaxial growth of three-dimensionally architectured optoelectronic devices. Nat. Mater. 10(9), 676 (2011).

10. R. Bhat: Current status of selective area epitaxy by OMCVD. J. Cryst. Growth 120(1-4), 362 (1992).

11. J.J. Boland and G.N. Parsons: Bond selectivity in silicon film growth. Science 256(5061), 1304 (1992).

12. S. Yu, E. Gulari, and J. Kanicki: Selective deposition of polycrystalline silicon thin films at low temperature by hot-wire chemical vapor deposition. Appl. Phys. Lett. 68(19), 2681 (1996).

13. W.L. Gladfelter: Selective metallization by chemical-vapor-deposition. Chem. Mater. 5(10), 1372 (1993).

14. M.J. Hampdensmith and T.T. Kodas: Chemical-vapor-deposition of metals 2. Selective CVD of metals. Chem. Vap. Deposition 1 (2), 39 (1995).

15. C.H. Liang, L.C. Chen, J.S. Hwang, K.H. Chen, Y.T. Hung, and Y.F. Chen: Selective-area growth of indium nitride nanowires on gold-patterned Si(100) substrates. Appl. Phys. Lett. 81(1), 22 (2002).

16. S.S. Fan, M.G. Chapline, N.R. Franklin, T.W. Tombler, A.M. Cassell, and H.J. Dai: Self-oriented regular arrays of carbon nanotubes and their field emission properties. Science 283(5401), 512 (1999)

17. T. Nishiyama, E.M. Kim, K. Numata, and K. Pak: Doping study on maskless selective direct growth of GaAs using low-energy focused ion beam. Jpn. J. Appl. Phys. 43(6A), Part 2, L716 (2004).

18. F. Allegretti, M. Inoue, and T. Nishinaga: In-situ observation of GaAs selective epitaxy on GaAs (111)B substrates. J. Cryst. Growth 146(1-4), 354 (1995).

19. Y. Suzuki, M. Shimoda, Y. Okada, and M. Kawabe: Formation of quantum dot structures by atomic hydrogen assisted selective area molecular beam epitaxy. Jpn. J. Appl. Phys. 36(11B), Part 2, L1538 (1997).

20. T. Sugaya, Y. Okada, and M. Kawabe: Selective growth of GaAs by molecular-beam epitaxy. Jpn. J. Appl. Phys. 31(6A), Part 2, L713 (1992).

21. D.H. Cho, M. Hachiro, Y. Abe, and K. Pak: Maskless selective epitaxy of $\operatorname{In}_{\mathrm{x}} \mathrm{Ga}_{1-\mathrm{x}}$ As using low-energy $\mathrm{In}_{0.15} \mathrm{Ga}_{0.85}$-FIB and As-4 molecular beam. J. Cryst. Growth 201, 610 (1999).

22. T. Nishinaga and G. Bacchin: Selective area MBE of GaAs, AlAs and their alloys by periodic supply epitaxy. Thin Solid Films $\mathbf{3 6 7}$ (1-2), 6 (2000).

23. W.T. Lee, D.S. Tsai, Y.M. Chen, Y.S. Huang, and W.H. Chung: Area-selectively sputtering the $\mathrm{RuO}_{2}$ nanorods array. Appl. Surf. Sci. 254(21), 6915 (2008).

24. J. Karthik, A.R. Damodaran, and L.W. Martin: Epitaxial ferroelectric heterostructures fabricated by selective area epitaxy of $\mathrm{SrRuO}_{3}$ using an $\mathrm{MgO}$ mask. Adv. Mater. 24(12), 1610 (2012).
25. E.A. Paisley, M.D. Losego, B.E. Gaddy, J.S. Tweedie, R. Collazo, Z. Sitar, D.L. Irving, and J.P. Maria: Surfactant-enabled epitaxy through control of growth mode with chemical boundary conditions. Nat. Commun. 2, 461 (2011).

26. E.A. Paisley, B.E. Gaddy, J.M. LeBeau, C.T. Shelton, M.D. Biegalski, H.M. Christen, M.D. Losego, S. Mita, R. Collazo, Z. Sitar, D.L. Irving, and J-P. Maria: Smooth cubic commensurate oxides on gallium nitride. J. Appl. Phys. 115(6), 064101 (2014).

27. H.S. Craft, R. Collazo, M.D. Losego, S. Mita, Z. Sitar, and J.P. Maria: Band offsets and growth mode of molecular beam epitaxy grown $\mathrm{MgO}$ (111) on $\mathrm{GaN}$ (0002) by x-ray photoelectron spectroscopy. J. Appl. Phys. 102(7), 074104 (2007).

28. H.S. Craft, J.F. Ihlefeld, M.D. Losego, R. Collazo, Z. Sitar, and J.P. Maria: $\mathrm{MgO}$ epitaxy on $\mathrm{GaN}$ (0002) surfaces by molecular beam epitaxy. Appl. Phys. Lett. 88(21), (2006).

29. M.D. Losego, H.S. Craft, E.A. Paisley, S. Mita, R. Collazo, Z. Sitar, and J-P. Maria: Critical examination of growth rate for magnesium oxide $(\mathrm{MgO})$ thin films deposited by molecular beam epitaxy with a molecular oxygen flux. J. Mater. Res. 25(4), 670 (2010).

30. M.D. Losego, S. Mita, R. Collazo, Z. Sitar, and J-P. Maria: Epitaxial calcium oxide films deposited on gallium nitride surfaces. J. Vac. Sci. Technol., B 25(3), 1029 (2007).

31. M.D. Losego, S. Mita, R. Collazo, Z. Sitar, and J-P. Maria: Epitaxial growth of the metastable phase ytterbium monoxide on gallium nitride surfaces. J. Cryst. Growth 310(1), 51 (2008).

32. J.J. Chen, M. Hlad, A.P. Gerger, B.P. Gila, F. Ren, C.R. Abernathy, and S.J. Pearton: Band offsets in the $\mathrm{Mg}_{0.5} \mathrm{Ca}_{0.5} \mathrm{O} / \mathrm{GaN}$ heterostructure system. J. Electron. Mater. 36(4), 368 (2007).

33. J.K. Gillespie, R.C. Fitch, J. Sewell, R. Dettmer, G.D. Via, A. Crespo, T.J. Jenkins, B. Luo, R. Mehandru, J. Kim, F. Ren, B.P. Gila, A.H. Onstine, C.R. Abernathy, and S.J. Pearton: Effects of $\mathrm{Sc}_{2} \mathrm{O}_{3}$ and $\mathrm{MgO}$ passivation layers on the output power of AlGaN/GaN HEMTs. IEEE Electron Device Lett. 23(9), 505 (2002).

34. Y. Irokawa, Y. Nakano, M. Ishiko, T. Kachi, J. Kim, F. Ren, B.P. Gila, A.H. Onstine, C.R. Abernathy, S.J. Pearton, C.C. Pan, G.T. Chen, and J.I. Chyi: $\mathrm{MgO} / \mathrm{p}-\mathrm{GaN}$ enhancement mode metaloxide semiconductor field-effect transistors. Appl. Phys. Lett. 84(15), 2919 (2004)

35. J.F. Ihlefeld, W. Tian, Z.K. Liu, W.A. Doolittle, M. Bernhagen, P. Reiche, R. Uecker, R. Ramesh, and D.G. Schlom: Adsorptioncontrolled growth of $\mathrm{BiFeO}_{3}$ by $\mathrm{MBE}$ and Integration with wide band gap semiconductors. IEEE Trans. Ultrason. Ferroelectr. Freq. Control 56(8), 1528 (2009).

36. H. Wu, J. Yuan, T. Peng, Y. Pan, T. Han, K. Shen, B.R. Zhao, and C. Liu: Control of the epitaxial orientation and reduction of the interface leakage current in $\mathrm{YMnO} / \mathrm{GaN}$ heterostructures. J. Phys. D: Appl. Phys. 42(18), 185302 (2009).

37. A. Posadas, J.B. Yau, C.H. Ahn, J. Han, S. Gariglio, K. Johnston, K.M. Rabe, and J.B. Neaton: Epitaxial growth of multiferroic $\mathrm{YMnO}_{3}$ on GaN. Appl. Phys. Lett. 87(17), 171915 (2005).

38. J.F. Ihlefeld, M. Brumbach, and S. Atcitty: Band offsets of $\mathrm{La}_{2} \mathrm{O}_{3}$ on (0001) GaN grown by reactive molecular-beam epitaxy. Appl. Phys. Lett. 102(16), 162903 (2013).

39. W. Yifeng, M. Jacob-Mitos, M.L. Moore, and S. Heikman: A $97.8 \%$ efficient GaN HEMT boost converter with $300-\mathrm{W}$ output power at $1 \mathrm{MHz}$. IEEE Electron Device Lett. 29(8), 824 (2008).

40. Y. Uemoto, M. Hikita, H. Ueno, H. Matsuo, H. Ishida, M. Yanagihara, T. Ueda, T. Tanaka, and D. Ueda: Gate injection transistor (GIT) - A normally-off $\mathrm{AlGaN} / \mathrm{GaN}$ power transistor using conductivity modulation. IEEE Trans. Electron Devices 54(12), 3393 (2007). 
41. W.A. Doolittle, G. Namkoong, A.G. Carver, and A.S. Brown: Challenges and potential payoff for crystalline oxides in wide bandgap semiconductor technology. Solid-State Electron. 47(12), 2143 (2003).

42. R. Collazo, S. Mita, R. Schlesser, and Z. Sitar: Polarity control of GaN thin films grown by metalorganic vapor phase epitaxy. Phys. Status Solidi C 2, 2117 (2005).

43. S. Mita, R. Collazo, A. Rice, R.F. Dalmau, and Z. Sitar: Influence of gallium supersaturation on the properties of GaN grown by metalorganic chemical vapor deposition. J. Appl. Phys. 104(1), 013521 (2008).

44. O.H. Nam, M.D. Bremser, T.S. Zheleva, and R.F. Davis: Lateral epitaxy of low defect density GaN layers via organometallic vapor phase epitaxy. Appl. Phys. Lett. 71(18), 2638 (1997).

45. G. Geneste, J. Morillo, and F. Finocchi: Ab initio study of $\mathrm{Mg}$ adatom and $\mathrm{MgO}$ molecule adsorption and diffusion on the $\mathrm{MgO}$ (001) surface. Appl. Surf. Sci. 188(1-2), 122 (2002).

46. G. Geneste, J. Morillo, and F. Finocchi: Adsorption and diffusion of $\mathrm{Mg}, \mathrm{O}$, and $\mathrm{O}_{2}$ on the $\mathrm{MgO}(001)$ flat surface. J. Chem. Phys. 122(17), 174707 (2005).

47. K.N. Lee, S.M. Donovan, B. Gila, M. Overberg, J.D. Mackenzie, C.R. Abernathy, and R.G. Wilson: Surface chemical treatment for the cleaning of AlN and GaN surfaces. J. Electrochem. Soc. 147(8), 3087 (2000).
48. M. Diale, F.D. Auret, N.G. van der Berg, R.Q. Odendaal, and W. D. Roos: Analysis of GaN cleaning procedures. Appl. Surf. Sci. 246(1-3), 279 (2005)

49. S.W. King, J.P. Barnak, M.D. Bremser, K.M. Tracy, C. Ronning, R.F. Davis, and R.J. Nemanich: Cleaning of AlN and GaN surfaces. J. Appl. Phys. 84(9), 5248 (1998).

50. K.M. Tracy, W.J. Mecouch, R.F. Davis, and R.J. Nemanich: Preparation and characterization of atomically clean, stoichiometric surfaces of n- and p-type GaN(0001). J. Appl. Phys. 94(5), 3163 (2003).

51. A.R. Smith, R.M. Feenstra, D.W. Greve, J. Neugebauer, and J.E. Northrup: Reconstructions of the $\mathrm{GaN}(000 \overline{1})$ surface. Phys. Rev. Lett. 79(20), 3934 (1997)

52. T.K. Zywietz, J. Neugebauer, and M. Scheffler: The adsorption of oxygen at GaN surfaces. Appl. Phys. Lett. 74(12), 1695 (1999).

53. I. Barin: Thermochemical Data of Pure Substances (VCH, New York, NY, 1989).

54. T.I. Koranyi, E. Magni, and G.A. Somorjai: Surface science approach to the preparation and characterization of model Ziegler-Natta heterogeneous polymerization catalysts. Top. Catal. 7 (1-4), 179 (1999).

55. W.F. Egelhoff, P.J. Chen, C.J. Powell, M.D. Stiles, R.D. McMichael, J.H. Judy, K. Takano, and A.E. Berkowitz: Oxygen as a surfactant in the growth of giant magnetoresistance spin valves. J. Appl. Phys. 82(12), 6142 (1997). 